\title{
Research Excellence: The Imperative Primers
}

\author{
Type of article: Conference abstract
}

Syed Tajuddin Bin Syed Hassan ${ }^{1}$, Saliza Mohd Elias², Jalalian Mehrdad ${ }^{3}$

1 Department of Nursing and Rehabilitation, Faculty of Medicine and Health Sciences, Universiti Putra Malaysia.

2 Department of Environmental and Occupational Health, Faculty of Medicine and Health Sciences, Universiti Putra Malaysia.

3 Mehrafarin Scientific Publishing, Kish Island, IR Iran.

Email: stshasan@upm.edu.my

\begin{abstract}
Research excellence characteristics are comprehensively delineated, encompassing creativity through transnationality and translation-capability. The research iterative primers of "Re" and "search" as the underlying push-engine, is briefly illustrated. Subsequently, a visual model depicting three major modules of the entire research tasking-process illustrates the need to balance the preparation and the rendition of data and interpretation components, through the mediating role of data capture. Traits of the primers characterising research excellence are consequently deliberated and discussed thoroughly using the acronym R-E-S-E-A-R-C-H. The initial three entities, RES, fittingly portray the literature review matrix; with reviewing of references through examining "slacks" or gaps in available literature. The $\mathrm{E}$ is then envisaged as representing exclusivity through ethical considerations; A as audience through imbibition of overt and covert objectives, to audit trail analysis; $\mathrm{R}$ as rationale through research frame (interpretive, analytical, simulative); $\mathrm{C}$ as encompassing creativity through coherence (tone, voice, style); and, $\mathrm{H}$ as the human factors- trailing from biases through needs/wants to influences. Optimising values of these primers are deemed imperative to achieve excellence in a research project process and outcome.
\end{abstract}

Keywords: Research excellence, visual model, research frame, research primers, research process.

\section{Declaration of conflicts}

This article is a keynote presented at the International Conference on Health Sciences and Medical Technologies 2017 ICHSMT'17.

\section{Authors' biography}

Prof Dr Syed Tajuddin Bin Syed Hassan Department of Nursing and Rehabilitation, Faculty of Medicine and Health Sciences, Universiti Putra Malaysia.

Dr Saliza Mohd Elias PhD, Department of Environmental and Occupational Health, Faculty of Medicine and Health Sciences, Universiti Putra Malaysia. 
Medical Technologies Journal, Volume: 1, Issue: 3, July-September 2017, Pages: 48-49. DOI:

https://doi.org/10.26415/2572-004X-vol1iss3p48-49

Dr. Md Jalalian Mehrdad, Director, Mehrafarin Scientific Publishing, Kish Island, IR Iran. Editor-in Chief of Electronic Physician Journal, Mashhad, IR Iran.

\section{References}

No references 